\title{
MOBILE PHONE INTERACTION TECHNIQUES FOR RURAL ECONOMY DEVELOPMENT - A REVIEW
}

E.EDIM AZOM AND N. MUYINGI HIPPOLYTE

(Received 20 January 2010; Revision Accepted 2, June 2009)

\begin{abstract}
Rural communities, especially in developing countries, are often neglected in terms of facilities and services that aid their social and economic development. This is evident even in software development processes, in that these groups of users or potential users' are often not taken into consideration. The resultant effect is that they may not use it or use it sparingly. The objective of this study is to identify the various researches on interaction techniques and user interface design as a first step to the design of suitable mobile interactions and user interfaces for rural users. This research project is also aimed at socio-economic development and adding value to mobile phone users in Dwesa, a rural community in South Africa. This paper presents a literature survey of interaction techniques and user-interfaces. An analysis of the interaction techniques with respect to their suitability, availability of technologies, user capabilities for implementation in a rural context is discussed. Descriptive statistics of users' current phones interaction facilities in the rural community which briefly illustrates users' experiences and capabilities in different interaction modes is also presented.
\end{abstract}

KEY WORDS: Interaction Techniques, Mobile phone, User Interface, ICT, Rural Development.

\section{INTRODUCTION}

ICT plays a significant role in the social and economic development of a people. This can clearly be seen in the impact it has made all over the world and the increase of the use of ICT infrastructures and services e.g. internet, desktop computers, cell phones, and personal digital assistants (PDAs)). For mobile phones alone, the estimated global subscription rates were 4 billion in 2008 and a great percentage of the users were from developing countries (ITU, 2008). More people live in rural areas than urban centers in developing countries (IFAD, 2008). With the rapid spread of mobile phones in developing countries, rural areas are potential markets for ICT service providers to explore through services that will empower the people socially and economically. The rural communities are usually inhabited by poor and low literate people. There is also poor government presence in terms of social amenities, and a low level of ICT services. Much effort is needed in order to provide be ICT products and services that will help to improve the social and economic impact on this group of users.

Mobile phones and services are viable tool for social and economic development of rural people (Patel et al., 2008). Software developers and service providers need to explore these potential markets to provide services that will enhance rural livelihood and local economy development for these diverse users. Mobile phone services are limited in use in rural communities, where most phone users only make and receive calls with their devices. This could be due to low literacy, technology illiteracy, applications not tailored to their needs, or poverty-related factors. It is therefore important for developers and service providers to explore ways of addressing these problems, so as to increase mobile device usability in the rural areas. They need to provide user interactions and interfaces with applications that will be intuitive, localized and aimed at improving the rural quality of life.

Several interaction techniques have been designed and implemented on both the desktop PCs and mobile devices, with each trying to make the devices more efficient and usable. These interactions also attempt to take the forms applicable to human-tohuman interactions, but the majorities are still focused on the urban users that are highly skilled and technology literate.

Our objective in this paper is to explore and identify the numerous efforts that have been made by researchers in mobile interaction techniques. This review is not exhaustive and is not limited to a single interaction technique. We will not completely ignore the interaction techniques on the desktop PC as some of them apply to and can be implemented on mobile platforms.

Reviews on interaction techniques had been done within different domains of interactions. Few reviews exist that cover a broad spectrum of interaction techniques on mobile devices. Some of these reviews include those that had been done on hand gesture (Pavlovic et al., 1997) and taxonomy of gestures (karam and Schraelfel, 2007). Other researchers reviewed vision-based interaction technique and its application in different areas of computing, such as in human motion analysis (Gavrila, 1999 \& Poppe, 2007), in motion estimation (Erol et al., 2007), motion of the eyes

E.Edim Azom, Telkom Centre of Excellence in De velopment E-commerce, Department of Computer Science, University of Fort Hare, Alice, Eastern Cape, South Africa

N. Muyingi Hippolyte, MTC Endowed Chair of ICT, School of Information Technology, Polytechnic of Namibia. 
(Duchowski, 2002), and facial expression analysis (Fasel and luetin, 2003). A review of user interfaces for vision-based interactions is presented in Quek (1995), Kratz and Ballagras (2007). A review of speech-based interactions is presented in Potamianos et al., (2004). In Jaimes and Sebe (2007) a review of the different developments in multimodal interaction techniques is presented, while Maquire (1999) surveyed the different guidelines used for user interface design.

The use of ICTs for social and economic development of the rural areas is receiving attention in the research community and government agencies. Mobile phone is affordable when compared to the desktop computer in rural areas. To this end, interaction techniques and user interfaces for such ICT products and services must be designed to use available facilities (e.g. mobile phones), meet users' interaction experiences, user capabilities and expectations. In this research, mobile interactions and user interfaces on a mobile commerce application will be developed. The aim of the review presented in this paper is to identify the different interaction techniques, analyze their suitability for implementation from the literature and a survey of the users' environment where this research is targeted. The objective of this research is to add value to mobile phone use, economic empowerment, and bring ICT closer to rural people.

\section{Graphics User Interface (GUI)}

The graphical user interface has dominated interface technology and interactions on the desktop and mobile systems for a long time now. The popularity of the GUI has made it the traditional medium for presentation of information within different computing platforms and applications. GUI is easy to understand and also helps to remove complexities during task performance. Most interaction techniques often use this medium to display information on the screen, while the interactions are performed using any of the interaction technique or a combination of techniques.

Keyboard interactions are usually the main modality of interaction on GUls. Other modalities usually combine with the keyboard, such as the pen, stylus, touch screen, hand writing, for effective interactions. Different methods and models for GUI design have been presented by different authors. These include modelbased design (Paterno and Santoro, 2003), unified interface design method (Savidis and Stephanidis, 2004), and pattern modeling (Nilson et al., 2006). The small QWERTY keypad on mobile devices is mostly used for interactions on GUls. Research efforts geared towards reducing key presses during tasks performance on GUI had recorded successes. They try to combine key presses with other modes of interaction in order to reduce the difficulty users may face during interactions. Benko et al.,(2006) describes a method where the finger is used for selection on a mobile device touch screen. Other examples include: finger touch interaction (Vogel and Baudisch, 2007), FluidT-mouse (Esenther and Ryall, 2006), "drag-and-pop and drag-and-pick" (Baudisch et al., 2003). The above interfaces are graphical presentations.
With a GUI, Luoma, (2003) describes "the symbol creator" that enabled users to perform text entry with ease. In Balakrishnan et al., (2008), the keypad is combined with a pen rolling technique to interact with a pen-based user interface. Some stylus-based interfaces that enable users enter text with ease and flexibility into their mobile devices include those discussed in Yatani and Truong, (2007), Glyph (Poirier, 2005), and Edgewrite (Wobbrock et al., 2003). Other forms of interaction modalities that were integrated with the mobile keypad to give users intuitive interactions on GUls are discussed (Rekimoto, 1996 \& Widgor and Balakrisnan, 2003). Rekimoto, (1996) described a tilt interface that enables interactions on small screen devices. The user tilts the device to the direction of an item that needed to be selected on the screen, and performs an input operation through key press and selection. Widgor and Balakrishnan, (2003) presented a GUI that allows the user to tilt the mobile phone to the direction of a character on the keypad and the movement is indicated on the screen. The desired character is then selected by pressing the key on the keypad that contains that character in its combination.

GUls are flexible and easy to use. This is demonstrated in Medhi et al., (2006) where it was implemented and used to assists illiterate and semiliterate users to search for jobs that are available within their community on the Web. The users were able to use the application with ease. A GUI on any application for rural community people and with the appropriate symbols that reflect the social and cultural values of the people could help to improve usability of new technology within the community.

\section{Vision-Based Interaction Technique}

Advances in mobile technologies have brought about promising features and functionalities. This has increased the modalities of interaction and services available on mobile devices. Some of these improvements include high resolution cameras, and detachable memory cards. High resolution cameras available on mobile devices can capture images of objects and used for interaction on mobile devices.

Vision-based interaction technique performs just like human sight (Kjeldsen et al., 2003) used for interaction with other humans or objects in our environment. This form of interaction on mobile devices is made possible through an interface provided on the device.

A vision-based interface that can detect head movement through a mobile phone camera is also described (Kjeldsen et al., 2003). Vision-based interaction and interface were applied in a mobile game application in Capin et al. (2006), while Bucolo et al. (2005) describe two interfaces for tilt and translation interactions on a mobile phone that are used to play a ball in the maze game which is made possible by the camera interface. In Hannuksela et al. (2007) a visionbased interface that is combined with the camera of the mobile phone to capture and measure the motion of the phone when it is tilted or translated on the hand is described. 
With the decrease in price of mobile phone devices and the increased distribution of camera equipped devices, the application of vision-based interactions and interfaces for low literate rural community people may be a possibility in the future. Vision-based interaction can be applied in traditional game applications that are localized to the rural people. This may provide the needed intuition and usefully add value to mobile phone usage within a low literate/community.

\section{Gesture-Based Interaction Technique}

Using gesture during oral communication is common among humans (Brewster et al., 2003). It is most times performed using different parts of the body, such as the head, hand, mouth, or eyes. There exist applications and services that use gesture as a mode of interaction both on the desktop computers and on mobile devices. Some examples are interactive games Kratz and Ballagras (2007), Sato et al. (2006), consumer electronics Bretzner et al. (2002) and virtual environments Vatavu et al. (2005).

Gesture-based user interfaces that enable users to interact with the computing system are also available. An interface that accepts head gestures as input for menu selection is presented Brewster et al., (2003). Wexelblat, (1995) used gestures as the modality of interaction on virtual reality systems, while Crossan and Murray-Smith (2004) incorporated an accelerometer in a gesture-based interface for interaction. In Long Jr. et al. (2000), a pen-based interface is combined with a gesture recognition module for user interactions. For mobile entertainment, Pirhonen et al. (2002) used gesture to control a mobile music player, and Crossan and Murray-Smith (2006) also describes how a song could be selected and filtered using gesture in a mobile phone music player that is attached with an accelerometer. On large display systems, Fohrnbach et al. (2008) describe the use of hand gesture for selecting items on the display through pointing of the finger on the target.

As a human form of communication that cuts across every society, this type of interaction can have some unique features among different groups. These gestures could be captured and used for interaction design for different mobile applications, but such facilities are not yet available in rural areas.

\section{Point and Shoot Interaction Technique}

Point and shoot interaction technique offers an intuitive method of interactions to the users. It is flexible and natural since as humans we also point to object we interact with. An interaction device is pointed to another object for interaction and exchange of information. Research work has been done in this regard such as discussed (Ballagas et al., 2005), where a mobile phone's camera is pointed to a target item or position on a large display screen to perform item selection, rotation/drag with the phone's joystick. Another example of this technique is a tourist application (Madhavepeddy et al., 2004) that allows mobile phone users to read the tags on a world map by pointing the camera on the tags and then shoot to select the target. With the information they could locate a city/airport, book a flight, or view a city map.

In Rukzio et al. (2006), a mobile phone camera is used to pick images of smart objects with visual markers for identification and the information concerning the smart object is read. Also, optical beam attached to a mobile phone is used to read information from visual tags on a poster through pointing (Valkkynen et al., 2003).

This type of interaction technique may still seem difficult to implement in a rural community due to the high technological requirements. But being an intuitive and easy form of interaction, it can be useful for wireless services like information boards where audio information can be transmitted to the user in his or her local language.

\section{Touch-Based Interaction Technique}

During interactions, we could touch other people or objects that are near to us. With mobile devices, this type of interaction has been demonstrated by researchers with objects like posters, maps with radio frequency identification (RFID) tags, information kiosks, public display systems, and near field communication (NFC) enabled mobile devices.

Touch-based interactions using mobile phones equipped with NFC/RFID tag readers can be used to interact with other objects at acceptable communication range as discussed (Hardy and Rukzio, 2008). Hannuksela et al. (2007) used a mobile phone to read information from a map-based tourist application in a large display system by touching the device on the display to get information from the map. In entertainment, Anokwa et al. (2007) describes the use of mobile phones enabled with NFC to interact with movie poster so as to enable the user book for the event. In Isomursu et al. (2008), a home care application where the elderly people could use NFC/RFID enabled mobile phones to order meals from a home care service provider by touching the phone on tags placed in their homes as a way of assisting them in their daily living is described. Rukzio et al. (2006) also used a mobile phone with RFID tag reader to browse information from a Web server by touching the device on an RFID tag. And in Hinckley et al. (2000), touch sensors attached to a mobile phone are used to send signals into the mobile phone when the user touch or pick the phone.

Touch-based interactions are easy to perform without requiring much assistance. In a rural community, this type of interaction technique could be useful since it does not require text commands. It could be implemented in mobile applications that provide community support services with user interface and requirements that meets the local needs of the people. Facilities for implementing this interaction technique in rural areas are not available yet.

\section{Speech-Based Interaction Technique}

Speech communication is a common, intuitive and natural way of interaction. Research efforts in speech technology had resulted in the development of 
different speech recognition and synthesis systems, and applications that uses these systems to improve speechenabled interactions. One prominent advantage of speech interactions is that it can accommodate a variety of users (Zhang et al., 1999).

The Mandarin dialog system (Tsai, 2006) is a voiceXML interface that provides users access to Web services with Mandarin or English language voice commands via telephone lines. The application uses automatic speech recognition and text-to-speech systems to establish dialogs between the user and the Web service. WAP (wireless application protocol) integration with speech technology provides wireless access to users using speech interactions. In Lo and Meng (2002), users with WAP devices could interact with the Web server to retrieve information and services such as weather information, stock alert service, or sport news using voice commands. Also, Sodnik et al. (2008) describes a driving simulator with an auditory interface on a mobile device.

In database systems, speech technology has been used to perform database queries. This is discussed in (Arons 1999), where voice queries are used to manipulate the database using the mobile phone, while D'Haro et al. (2006) describes a Webbased database system that perform queries using voice commands.

Speech-based interfaces enable device users to simultaneously engage in more than one activity (Holland et al., 2002). In rural communities, speech interactions on mobile devices may provide the desired intuition, flexibility and ease of use. An example is Sherwani et al. (2007), where a voice-enable application is used to assists a rural community in Pakistan to access health information from the Internet. Speech applications on mobile devices can be applied in any rural community provided the language of communication or interaction is localized.

\section{Multi-Modal User Interface}

Multimodal user interfaces combines two or more modality of interaction for user interactions. They can accommodate diverse users since they provide more than one modality of interaction to them. Multimodal interfaces can be implemented in different application areas.

Multimodal interfaces that combine speech and gestures interactions were implemented (Bolt, 1980, Ito, 2001, and Irawati et al., 2006) for intuitive interactions in different applications. In Bolt (1980), speech and pointing gestures are used for positioning objects on a large display system, while Zhang, (1999) combined these two modalities of interaction to assist the visually impaired to control home appliances, and Irawati et al. (2006) applied speech and gesture interfaces in augmented reality environment to provide intuitive interactions to the user.

MUNDO (Hartl et al, 2002) is a multimodal interface development tool for different applications on mobile devices. A multimodal user interface is a good candidate interface that can be used to improve mobile phone usability in any rural community in developing countries. A combination of speech and GUI on an ecommerce application can assist low literate users to use the system effectively. This had been demonstrated and proven successful (Sherwani et al, 2007).

\section{Summary}

The interaction techniques so far discussed are applicable on both desktop Pc; wireless and mobile devices. Some of the interactions are yet to receive wide acceptability on the mobile device due to the limited nature of the device and the wide use of mobile devices such as the mobile phone across different variety of users. These techniques have tried to take interactions design to higher level. Though they have all been describe to follow the natural ways of human interactions and also aimed at improving interactions and users' experiences with their devices. Much research work is still needed to evaluate their effectiveness and user satisfaction impact (Ji et al., 2006 \& Duh et al., 2006). Although, research in user interface design is still faced with the problem of designing interfaces that can provide the needed satisfaction and the right context of use for every user (Cremers et al, 2007) irrespective of their physical abilities, educational background and environment.

A summary of the different interaction techniques, the types of interaction, input and output mechanisms associated with the different techniques are presented below. We also mentioned the interaction suitability/non-suitability for implementation on mobile devices for rural mobile phone users taking into consideration factors such as low income, technology illiteracy, low literacy level, availability of facilities and user needs.

\section{Touch-based interactions}

Type of interaction: Instant or continuous touch on an interaction surface, e.g. a mobile device screen surface or on an interaction object for connection together. Some existing application areas: Mobile tourist guide, home care services, advertisements, museum guides, etc. Input mechanisms plus support facilities: Mobile devices enabled with NFC, RFID readers, Bluetooth, sleep/active mode display etc.

Output mechanisms plus support facilities: Mobile device screen, large display system/dynamic display system etc. Suitability for use during movement: Not suitable for use during movement. Interactions are performed when stationary. User requirements (illiteracy; less training; intuitiveness "localization"): Less pre-knowledge of displayed options required; intuitive, difficult localization/personalization. Suitability in a rural community: Not yet Suitable for implementation in rural areas, due to none availability of facilities rural communities. It also requires some level of literacy and training.

Gesture-based interactions

Type of interactions: Movement of human body e.g. the arm, camera movement, image capturing on camera. Some existing application areas: Interactive games, virtual environments, control of music players, camerabased recognition systems etc. Input mechanisms plus 
support facilities: Mobile device camera, sensor-enabled mobile device, accelerometer, etc. Output mechanisms plus support facilities: Mobile device screen, large display systems, virtual reality systems, etc. Suitability for use during movement: Interactions can be perform during movement. User requirements (illiteracy; less training; intuitiveness "localization"): Intuitive, unknown outcome of input; requires knowledge of possible input, difficult localization. Suitability in a rural community: Difficult and may not yet be suitable for implementation, facilities or devices may be too costly for rural people.

Vision-based interactions

Type of interactions: Instant or continuous movement of camera or objects, image capturing. Some existing application areas: Mobile games, tourist guide, advertisements, video mails, etc. Input mechanisms plus support facilities: Mobile device camera, data gloves, NFC/RFID reader, etc. Output mechanisms plus support facilities: Mobile device screen, virtual reality display systems. Suitability for use during movement: Interaction is not suitable during movement. User requirements (illiteracy; less training; intuitiveness "localization"): Unknown outcome of input; requires knowledge of possible input, difficult localization. Suitability in a rural community: Not suitable yet for implementation due to limited facilities and interaction complexity that will require training.

Point and Shoot interactions

Type of interactions: Instant shooting; mobile device is pointed to object of interaction, selection, clicking an item. Some existing application areas: Tourist guide, Web services, Advertisement, games, etc. Input mechanisms plus support facilities: Mobile device camera, optical beams/light beams, laser pointers, etc. Output mechanisms plus support facilities: Mobile device screen, large display systems, etc. Suitability for use during movement: Interactions not suitable during movement. User requirements (illiteracy; less training; intuitiveness "localization"): Unknown outcome of input; requires knowledge of possible input, difficult localization. Suitability in a rural community: Not suitable for implementation, devices are costly and unavailable in rural areas etc.

Speech-based interactions

Type of interactions: Spoken dialog and voice commands, and sometimes with key presses for interactions. Some existing application areas: Wide range of applications, games, Web services, database queries, tourist guide, etc. Input mechanisms plus support facilities: Mobile device microphone or mouth piece. Output mechanisms plus support facilities: Mobile device screen, speaker or earpiece. Suitability for use during movement: Suitable for use during movement. User requirements (illiteracy; less training; intuitiveness "localization"): Intuitive, low literacy level; linguistic localization. Suitability in a rural community: Suitable for implementation in rural areas.

Graphic User interface

Type of interactions: Keypad pressing, mouse pointer and button press with device movement, finger touch, stylus, pen interactions, etc. Some existing application areas: Wide range of applications, games, Web services, database queries, tourist guide, etc. Input mechanisms plus support facilities: keypad, touch screen, stylus, pen, etc. Output mechanisms plus support facilities: Mobile device screen.

Suitability for use during movement: Cumbersome and not flexible enough for use during movement. Often used with conflicting attention. User requirements (illiteracy; less training; intuitiveness "localization"): Intuitive; low literacy, ease cultural localization. Suitability in a rural community: Suitable for implementation, but with minimal key presses.

Multimodal interactions

Type of interactions: Keypad/button pressing, voice/keypad, vision/gestures, pointer selection with narrator interaction, and other combination of interaction types. Some existing application areas: Wide range of applications, games, Web services, database queries, tourist guide, etc. Input mechanisms plus support facilities: keypad, touch screen, stylus, pen, help desk; narrator or screen navigator or drop down menu, etc. Output mechanisms plus support facilities: Mobile device screen; screen narrator, speaker, etc. Suitability for use during movement: Less conflicting attention with narrator. User requirements (illiteracy; less training; intuitiveness "localization"): Intuitive; low literacy, ease cultural localization. Suitability in a rural community: Suitable for use in a rural community.

\section{Survey of Users' Phone Interaction Mode}

We conducted a survey using structured questionnaire with the target users in the rural community to find out users' different modes of interacting with their devices, as a means of determining their capabilities and experience with mobile phone technology with respect to the different interaction techniques. This is part of the user and environmental analysis in our study. The result shows that among the 83 respondents, $78.13 \%$ owned mobile phones and interact with the primary keypad and screen. For additional phone facilities, $12.5 \%$ use touch screen, $6.25 \%$ use touch pen for interaction, $60.87 \%$ use camera on their device, and $12.5 \%$ also interact with soft keypad on their phone. The results are indications of the nature of phones, common interaction technologies used, and users' capabilities with phone technologies.

\section{CONCLUSION}

The rapid proliferation of mobile phones entails that new applications are required to take advantage of the new market. ICT can play a significant role in rural development by providing services that take into consideration the local economy of the people. The type of user interface and interaction technique used will play a vital role in this. We have presented a review of some of the existing research on interactions and interface design as part of our research work to design mobile interactions and user interface for ICT services for rural users.

Our future work is to design graphic and voice interfaces for mobile commerce services for rural users in Dwesa community of South Africa consisting of semi and illiterate mobile phone users, and subsistence 
farmers. This is part of the Siyakhula Living Lab project an ICT infrastructure that have been installed in Dwesa to provide Internet access and a platform for social research aimed at socio-economic enhancement of the community.

\section{REFERENCES}

Anokwa, Y., Borriello, G., Pering, T. and Want, R., 2007. A user interaction model for NFC enabled applications. In Proceedings of the $5^{\text {th }}$ IEEE International Conference on Pervasive Computing and Communications Workshop, White Plains, NY, USA, pp.357-361.

Arons, B., 1991. Authoring and Transcription Tools for Speech-Based Hypermedia Systems. In Proceedings of Conference, American Voice I/O Society, pp.15-20.

Ballagas, R., Rohs, M., and Sheridan, J., 2005. Mobile Phones as Pointing Devices. In Proceedings of Pervasive 2005 Workshop on Pervasive Mobile Interaction Devices, pp.27-30.

Baudish, P., Cutrell, E., Robbins, D., Czerwinski, M., Tandler, P., Bederson, B., and Zierlinger, A., 2003. Drag-andpop and drag-and-pick: techniques for accessing remote screen content on touchand pen-operated systems. In Proc. of Interact, pp.57-64.

Benko, H., Wilson, A. D and Baudisch, P. 2006. Precise Selection Techniques for Multi-Touch Screens. In Proc. Of CHI . Pp.1263-1272.

Balakrishnan, R., Bi, X., Moscovich, T., Ramos, G. and Hinckley, K., 2008. An Exploration of Pen Rolling for Pen-based Interaction. In proc. of the 21st annual ACM symposium on User interface software and technology, pp.191-200.

Bolt, R. A., 1980. Put-That-There: Voice and Gesture at the Graphics Interface. In Proceedings of ACM SIGGRAPH,Computer Graphics, 14: 262-270, In: Irawati, S., Green, S., Billinghurst, M., Duenser, A. and Heedong, K. 2006. Move the couch where?" developing an augmented reality multimodal interface, In ISMAR ‘06, pp.183-186.

Bretzner, L., Laptev, I., and Lindeberg, T., 2002. Hand Gesture Recognition using Multi-Scale Colour Features, Hierarchical Models and Particle Filtering. In Proc. of IEEE Intl. Conf. on Automatic Face and Gesture Recognition, pp. $423-428$.

Brewster, S., Lumsden, J., Bell, M., Hall, M. and Tasker, S., 2003. Multimodal "Eyes-Free" Interaction Techniques for Wearable Devices. In Proc. Of CHI-Conference, pp.473-480.
Bucolo, S., Billinghurst, M. and Sicklinger, D., 2005. User Experiences with Mobile Phone Camera Game Interfaces. In Proc. of the 4th international conf. on Mobile and ubiquitous multimedia, pp.87-94.

Capın, T., Haro, A., Setlur, V., and Wilkinson, S. 2006. Camera-Based Virtual Environment Interaction on Mobile Devices Lecture Notes in Computer Science, 4263: 765-773.

Cremers, A. H. M., de Jong, J. G. M., and van Balken, J. S., 2008. User-Centered Design with Illiterate

Persons: The Case of the ATM User Interface. In: proc. of international conference on computers for handicapped persons, 713720 .

Crossan, A., and Murray-Smith, R. 2004. Variability in Wrist-Tilt Accelerometer-based Gesture Interfaces. Proc. of MobileHCl'04, Glasgow, Springer-Verlag, pp.144-155.

Crossan, A. and Murray-Smith, R. 2006. Rhythmic Interaction for Song Filtering on a Mobile Device. In Proc. Haptic and Audio Interaction Design, First International Workshop, HAID, pp.45-55.

D'Haro, L. F., de Cordoba, R., Ferreiros, J., Hamerich, S. W., Schless, V., Kladis, B., Schubert, V., Kocsis, O., Igel, $S$ and Pardo, J. M. 2006. An advanced platform to speed up the design of multilingual dialog applications for multiple modalities. Speech Communication, 48: 863-887.

Duchowski, A. T., 2002. A Breadth-First Survey of Eye Tracking Applications. Behavior Research Methods, Instruments, and Computing, 34(4): 455-470.

Duh, H. B., Tan, G. C. B., and Chen, V. H., 2006. Usability evaluation for mobile device: a comparison of laboratory and field tests. In: Proc. of the $8^{\text {th }}$ conference on Humancomputer interaction with mobile device and services. Pp.181-186.

Erol, A., Bebis, G., Nicolescu, M., Boyle, R. D. and Twombly, X., 2007. Vision-based hand pose estimation: A review. Computer Vision and Image Understanding, 108: 52-73.

Esenther, A. and Ryall, K. 2006. Fluid DTMouse: Better Mouse Support for TouchBased Interactions. In Proceedings of Advanced Visual Interfaces (AVI), pp.112-115. 
Fasel, B. and Luettin, J., 2003 Automatic facial expression analysis: A Survey. Pattern Recognition, 36(2): 259-275.

Fohrenbach, S., Konig, W. A., Gerken, J. and Reiterer, H., 2008. Natural Interaction with Hand Gestures and Tactile Feedback for large, high $\square$ res Displays. In Proc. Of MITH'08: Workshop on Multimodal Interaction Through Haptic Feedback, held in conjunction with AVI'08: International Working Conference on Advanced Visual Interfaces, Napoli, Italy, pp.102-114.

Gavrila, D. M., 1999. The visual analysis of human movement: a survey. Computer Vision and Image Understanding 73(1): 82-98.

Hardy, R. and Rukzio, E., 2008. Touch \& Interact: Touch-based Interaction of Mobile Phones with Displays, In Proc. Of 10th International Conference on Human-Computer Interaction with Mobile Devices and Services (Mobile $\mathrm{HCl})$, pp.2-5.

Hannuksela, J., Pekka, P. S. and Heikkila, J., 2007. Vision-based motion estimation for interaction with mobile devices, Computer Vision and Image Understanding, 108: 188-195.

Hartl, A., Aitenbichler, E., Austaller, G., Heinemann, A., Limberger, T., Braun, E., and Muhlhauser, M., 2002.

Engineering Multimedia-Aware Personalized Ubiquitous Services. In Proc. of fourth IEEE symposium on multimedia software enginee ring, pp.344-351.

Hinckley, K., Pierce, J., Sinclair, M. and Horvitz, E., 2000. Sensing techniques for mobile interaction. In Proceedings of User Interface Software and Technology (UIST), pp.91-100.

Holland, S., Morse, R. D. and Gedenryd, H. 2002. AudioGPS: Spatial Audio Navigation with a Minimal Attention Interface,.Personal and Ubiquitous Computing, 6: 253-259.

(IFAD) International Fund for Agricultural Development Rural poverty in Africa, Oct. 2008. Available:

http://www.ruralpovertyportal.org/english/regio ns/Africa/index.htm.

(ITU-T) International Telecommunication Union World Wide mobile phone subscription, Aug., 2008. Available:

http://www.chinapost.com.tw/business/global market/2008/05/26/158188/mobile-phone.htm.

Irawati, S., Green, S., Billinghurst, M., Duenser, A. and Heedong, K., 2006. Move the couch where?" developing an augmented reality multimodal interface. In ISMAR '06, pp.183-186.
Ito, E., 2001. Multi-modal Interface with Voice and Head Tracking for multiple home appliances. In proc. of INTERACT $20018^{\text {th }}$ FIP TC. 13 conferences on Human-computer interaction, pp.727-728.

Isomursu, M., Haikio, J., Wallin, A. and Ailisto, H., 2008. Experiences from a Touch-Based Interaction and Digitally Enhanced Meal-Delivery Service for the Elderly. Advances in Human-Computer Interaction, ID 931701. Available: http://www.hindawi.com/getpdf.aspx?doi=10.1 155/2008/931701.

Jaimes, A. and Sebe, N., 2007. Multimodal humancomputer interaction: A survey. Computer vision and image understanding, 108: 116134.

Ji, Y. G., Park, J. H., Lee, C. and Yun, M. H., 2006. A usability checklist for the usability evaluation of mobile phone user interface. Int'l Journal of Human-computer interaction, 20(3): 207-231.

Karam, M. and Schraefel, M. C., 2007. A Taxonomy of Gestures in Human Computer Interactions. Technical Report ECSTR-IAM05-009, Dept. of Electronics and Computer Science, University of Southampton. $41 \mathrm{pp}$.

Kjeldsen, R., Levas, A., and Pinhanez, C., 2003. Dynamically Reconfigurable Vision- Based User Interfaces. In Proc. of 3rd International Conference on Vision Systems (ICVS'03), Springer-Verlag, pp.323-332.

Kratz, S. and Ballagas, R., 2007. Gesture Recognition Using Motion Estimation on Mobile Phones. In Proc. of 3rd International Workshop on Pervasive Mobile Interaction Devices (PERMID), Toronto, Ontario, Canada.

Lo, T. and Meng, H. M., 2002. WAP-Speech: Deriving Synergy between WAP and the Spoken Dialog Interface. In Proc. of the Eleventh International World Wide Web Conference. Honolulu, Hawaii, USA.

Long Jr., C. A., Landay, J. A., Rowe, L. A. and Michiels, J., 2000. Visual Similarity of Pen Gestures. In Proceedings of the SIGCHI conference on Human factors in computing systems, ACM Press, pp. $360-367$.

Luoma, M., 2003. Symbol Creator: Usability Evaluation of the Novel Pen-Based Text Input Technique, Technical Notes on New Interaction Techniques, University of Tampere.Available http://www.cs.uta.fi/ grse/NIT 2003/Student prjs/Melind L/SymbolCreator.pdf 
Madhavapeddy, A., Scott, D. Sharp, R and Upton, E., 2004. Using camera-phones to enhance humancomputer interaction. In proc. Sixt International Conference on Ubiquitouse 160 Computing (Adjunct Proc.).

Maguire, M. C., 1999. A review of user-interface design guidelines for public information kiosk systems. Int'll Journal of Human-Computer interaction, 50(3): 263-286.

Medhi, I., Sagar, A. and Toyama, K. 2006. Text-Free User Interfaces for Illiterate and Semi-Literate Users. In Proc. International Conference on Information and Communications Technologies and Development, pp.72-82.

Nilsson, E. G., Floch, J., Hallsteinsen, S. and Stav, E., 2006. Model-base user interface adaptation. Computer and Graphics, 30: 692-701.

Patel, N., Agarwal, S., Rajput, N., Kumar, A., Nanavati, A., Dave, P. and Parikh, T. S. 2008. Experiences Designing a Voice Interface for Rural India. In proceedings of the IEEE Workshop on Spoken Language Technology for Development (SLT), pp.2125.

Paterno, F. and Santoro, C., 2003. A unified method for designing interactive systems adaptable to mobile and stationary platforms. Interacting with Computers, 15: 349-366.

Pavlovic, V. I., Sharma, R. and Huang, T. S., 1997. Visual Interpretation of Hand Gestures for Human-Computer Interaction: A Review. IEEE Transactions on Pattern Analysis and Machine Intelligence, 19: 677-695.

Pirhonen, P., Brewster, S. A. and Holguin, C., 2002. Gestural and audio metaphors as a means of control in mobile devices. In Proc. of $\mathrm{CHI}$ 2002, ACM Press, pp.291-298.

Poirier, F., 2005. Glyph: A New Stroke-Alphabet for Stylus-Based or Key-Based Text Entry. In Proc. of International Conf. on $\mathrm{HCl}$, Las Vegas, USA, 2005.

Poppe, R., 2007. Vision-based human motion analysis: An overview. Computer Vision and Image Understanding, 108: 4-18.

Potamianos, G., Neti, C., Luettin, J. and Matthews, I., 2004. Audio-visual automatic speech recognition: An overview. In Issues in Visual and Audio-Visual Speech Processing. MIT Press.

Quek, F. K. 1995. Eye in the interface, Image and Vision Computing, 13(6) 511-525.
Rekimoto, J., 1996. Tilting Operations for Small Screen Interfaces (Tech Note). In Proc. of UIST-1996, pp.167-168.

Rukzio, E., Leichtenstern, K., Callaghan, V., Holleis, P., Schmidt, A. and Chin, J., 2006. An experimental comparison of physical mobile interaction techniques: touching, pointing and scanning. In Proceedings of the Eighth International Conference on Ubiquitous Computing (Ubicomp ‘06), pp.87-104.

Sato, T., Fukuchi, K. and Koike, H., 2006. Camerabased Flicking Gesture Recognition and Game Applications. ACM User Interface Software and Technology, demonstration paper.

Savidis, A and Stephanidis, C., 2004. Unified user interface design: designing universally accessible interactions. Journal of Interacting with Computers, 16: 243-270.

Sherwani, J., Ali, N. Mirza, S., Fatma, A., Memon, Y., Karim, M., Tongia, R. and Rosenfeld, R., 2007. HealthLine: Speech -based Access to Health Information by Low-literate Users. In Proc. Int'l conf. of Information \& Communication Technologies and Development, Bangalore, India. Available: http.//ww.cs.cmu.edu/ isherwan/pubs/ictd07.p df

Sodnik, J., Dicke, C., Tomazic, S. and Billinghurst, M., 2008. A user study of auditory versus visual interfaces for use while driving. Int. Journal of HumanComputer Studies, 66: 318-332.

Tsai, M., 2006. VoiceXML dialog system of the multimodal IP-telephony - The application for voice ordering service. Journal of Expert systems with application, 31: 684-696.

Valkkynen, P., Korhonen, I., Plomp, J., Tuomisto, T., Cluitmans, L., Ailisto, H and Seppa, H., 2003. A user interaction paradigm for physical browsing and near-object control based on tags. In Proc. of Physical Interaction (PI03) Workshop on Real World User Interfaces (The Mobile $\mathrm{HCl}$ Conference), pp,31-34.

Vatavu, R. D., Pentiuc, S. and Chaillou, C., 2005. On natural gestures for interacting in virtual environments, Advances in Electrical and Computer Engineering. Issue 2, 5(12): 72-79.

Vogel, D. and Baudisch, P., 2007. Shift: A Technique for Operating Pen-Based Interfaces Using Touch. In Proc. of CHI. Available: http://research.microsoft.com/enus/um/people /baudisch/publications/2007-vogel-chi07shift.pdf 
Wexelblat, A., 1995. An Approach to Natural Gesture in Virtual Environments. ACM Transactions on Computer-Human Interaction, 2(3):179-200.

Wigdor, D. and Balakrishnan, R., 2003. TiltText: Using tilt for text input to mobile phone. In Proceedings of the $16^{\text {th }}$ annual ACM symposium on User interface software and technology, ACM Press, pp.81-90.

Wobbrock, J. O., Myers, B. A. and Kembel, J. A., 2003. EdgeWrite: A Stylus-Based Text Entry Method Designed for High Accuracy and Stability of Motion. ACM UIST-2003, pp.61-70.
Yatani, K. and Truong, K. N., 2007. An Evaluation of Stylus-Based Text Entry Methods on Handheld Devices in Stationary and Mobile Settings. In Proc. Of the $9^{\text {th }}$ Int'l. Conf. on $\mathrm{HCl}$ with Mobile Devices and Service, ACM Press, pp.487-494.

Zhang, W., Duffy, V. G., Linn, R. and Luximon, A., 1999. Voice recognition based human-computer interface design. Computer and industrial engineering, 37: 305-308. 